
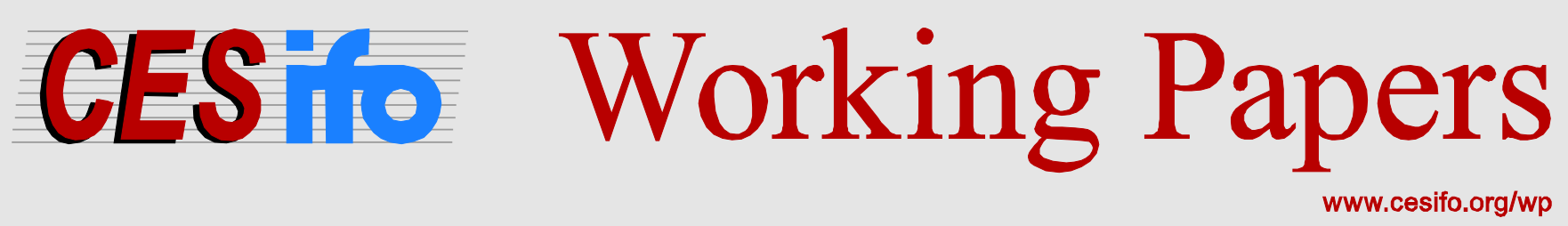

\title{
Climate Change and Psychological Adaptation: A Behavioral Environmental Economics Approach
}

\author{
Thomas Aronsson \\ Ronnie Schöb
}

\author{
CESIFO WORKING PAPER No. 4795 \\ CATEGORY 10: ENERGY AND CliMATE ECONOMICS \\ MAY 2014
}
An electronic version of the paper may be downloaded
- from the SSRN website: Www.SSRN.com
- from the RePEc website: Www.RePEc.org
- from the CESifo website: www.CESifo-group.org/wp

\section{CESifo}




\title{
Climate Change and Psychological Adaptation: A Behavioral Environmental Economics Approach
}

\begin{abstract}
Economic models of climate policy (or policies to combat other environmental problems) typically neglect psychological adaptation to changing life circumstances. People may adapt or become more sensitive, to different degrees, to a deteriorated environment. The present paper addresses these issues in a simple model of tax policy to combat climate change and elaborates on the consequences for optimal climate policies and argues from a normative point of view that psychological adaptation needs to be taken into account by a pure welfarist government, which aims at internalizing an intertemporal externality.
\end{abstract}

JEL-Code: D030, D610, D910, H210.

Keywords: behavioral environmental economics, climate change, intertemporal externalities, adaptation, sensitization, taxation.

Thomas Aronsson

Department of Economics

Umeå School of Business and Economics

Umeå University

Sweden - 90187 Umeå

Thomas.Aronsson@econ.umu.se
Ronnie Schöb

School of Business and Economics

Free University Berlin

Germany - 14195 Berlin

Ronnie.Schoeb@fu-berlin.de

May 2014

The authors would like to thank David Granlund and Daniel Nachtigall for helpful comments and suggestions. Aronsson would like to thank the Swedish Research Council (ref 421-20101420) for generous research grants. 


\section{Introduction}

One way to reduce the negative consequences of climate change is to adapt to new circumstances. Adaptation played an important role in the early policy discussions on climate change, but adaptation as a policy option was later fiercely opposed and the focus of climate policy shifted almost exclusively to curbing greenhouse gas emissions (Pielke et al. 2007). Taking adaptation into account was discredited as a "kind of laziness, an arrogant faith in our ability to react in time to save our skins” according to Al Gore (1992, p. 240). Only recently, economists began to also focus on the role of adaptation, and adaptation now ranks much higher on the political agenda (see, e.g., OECD 2008, 2012, IPCC 2007, 2014). In the latest report of the IPCC Working Group II, adaptation to climate change is described as "the process of adjustment to actual or expected climate and its effects. In human systems, adaptation seeks to moderate or avoid harm or exploit beneficial opportunities. In some natural systems, human intervention may facilitate adjustment to expected climate and its effects.” (IPCC 2014, p. 5). According to the Stern Review (Stern 2007), adaptation is "crucial to deal with the unavoidable impacts of climate change to which the world is already committed”. It has thus to be included in a comprehensive cost-benefit analysis of climate change policies. Adaptation encompasses a wide range of policy measures, such as building dikes that protect the landscape, developing vaccines to protect the population from diseases that spread as a consequence of climate change, improving general health conditions to increase the ability of coping with extreme weather conditions, changing urban architecture or building standards, reorganizing farming, and so on (Konrad and Thum 2014, p. 33).

This classification leaves aside one important aspect of adaptation: psychological adaptation to changing life circumstances. What is distinctive about psychologal adapation is that (on an individual level) it encompasses psychological reactions such as "appraisals of situations, affective responses, cognitive analysis and reframing, disengagement, defensive responses, and emotion regulation” (Reser and Swim 2011, p. 278). Affective or hedonic adaptation mainly affects our emotional experiences and might be highly reactive toward shortterm changes. Emotions "function as an "online” monitoring system of people's progress toward their goals and strivings ... but to retain its informational functionality, it must adapt 
quickly to long-term changes.” (Luhmann et al 2012, p. 593). ${ }^{1}$ People adapt to some negative experiences completely, but adapation may neither be complete nor inevitable, may occur at different paces, and there may be considerable individual differences in the degree to which people adapt (see Frederick and Loewenstein 1999, Diener, Lucas, and Scollon 2006, Lucas 2007, Lyubormirsky 2011). Furthermore, although changing external circumstances will hardly have a long-lasting effect on the affective well-being, they may have long-lasting effects on the cognitive well-being. However, people may eventually also adapt cognitively if they find an explanation for the event (Wilson and Gilbert 2008). ${ }^{2}$

In forecasting adaptive processes we do not do very well. According to Wilson and Gilbert (2003), people can correctly anticipate the valence of future feelings and specific emotions (such as joy or sadness) but make systematic errors in predicting the intensity and durability of feelings. Riis et al. (2005), for instance, show that healthy people fail to anticipate hedonic adaptation to poor health. So do Sackett and Torrance (1978) who find that healthy people evaluate one additional life year as a dialysis patient as being equivalent of living 0.39 additional years as a healthy person, while patients who actually suffer from dialysis evaluate one additional year of their current life as equivalent of living 0.56 additional healthy years. In an example, related to climate (change), Schkade and Kahneman (1998) asked people from Midwest and Southern California to rate their own life satisfaction and the life satisfaction of someone similar in the other region. It turned out that climate-related questions were more important for someone living in the other region than for someone living in the own region. Apparently, climate is more important in evaluating some imaginary situation than in actual well-being. Such a 'focusing illusion' is paraphrased by Kahneman and Thaler (2006) as "nothing in life matters quite as much as you think it does while you are thinking about it."

Psychological adaptation is omnipresent and thus also relevant with respect to the consequences of climate change. The American Psychological Association Task Force on the Interface between Psychology and Global Climate Change (2010) asked how people adapt to

\footnotetext{
${ }^{1}$ Evolutionary explanations for the emergence of hedonic adaptation are elaborated by Robson (2002), Rayo and Becker (2007) and Perez-Truglia (2012).

${ }^{2}$ Finally, psychological adaptation processes can also occur on a collective level, by social and situation-specific processes, such as collective sense making, social comparison, social construction, social amplification of risk, and collective efficacy (Reser and Slim 2011).
} 
and cope with the perceived threat and unfolding impacts of climate change and, in a comprehensive report about the current state of environmental psychology's contribution to climate change research, emphasized the psychological aspects of adapting and coping with climate change. As such, it also addressed the way in which the assessment of the consequences of climate change is influenced.

"Adapting to and coping with climate change is an ongoing and ever-changing process that involves many intrapsychic processes that influence reactions to and preparations for adverse impacts of climate change, including chronic events and disasters. Psychological processes include sense making; causal and responsibility attributions for adverse climate change impacts; appraisals of impacts, resources, and possible coping responses; affective responses; and motivational processes related to needs for security, stability, coherence, and control. These processes are influenced by media representations of climate change and formal and informal social discourse involving social construction, representation, amplification, and attenuation of climate change risk and its impacts. These processes reflect and motivate intrapsychic responses (e.g., denial, emotion management, problem solving) and individual and community behavioral responses. Individual and cultural variation influences all aspects of the process, providing context, worldviews, values, concerns, resilience, and vulnerability.” American Psychological Association Task Force on the Interface between Psychology and Global Climate Change 2010, p. 7)

This paper discusses the implications that the incorporation of psychological adaptation to climate change may have on the cost-benefit analysis of climate policy, in which we have to weigh the cost of today's measure to combat global warming against the cost borne by future generations resulting from climate change. These future costs should not be assessed in the way we perceive them today, but be based on how psychological adaptation will affect the way in which they are perceived by future generations. If we were to assess the future disutility of future pollution based solely on today's experiences, we would most likely over-estimate the welfare cost of future environmental damage, as we do not correctly anticipate psychological adaptation. The opposite argument applies to cases where people become more sensitive to the environmental damage over time, where assessment based solely on current experiences may 
lead to under-estimation of the future welfare costs of environmental damage. ${ }^{3}$ Therefore, irrespectively of whether adaptation or sensitization occurs, the environmental policy will be misspecified if we do not take account of these psychological processes.

In Sections 2 and 3, we develop a model that allows us to analyze the impact psychological adaptation to climate change can have on optimal intertemporal tax policies to fight the consequences of climate change. In Section 4, we extend the analysis to the case where people differ with respect to their ability to adapt. Section 5 dicusses the positive and normative implications of including hedonic adaptation into the cost-benefit analysis of climate change.

\section{The model}

This section presents a simple model with stock pollution, where production today leads to environmental damage in the future, and where the consumers may either adapt or sensitize to the environmental damage through a habit-formation process. The three agent types are consumers, firms, and the government, which are characterized below.

\section{Individuals and firms}

Consider an overlapping generations (OLG) economy where each individual lives for two periods. An individual of generation $t$ is young in period $t$ and old in period $t+1$, and enjoys utility from his/her consumption when young, $c_{t}$, leisure when young, $z_{t}$, and consumption when old, $x_{t+1}$. The individual also derives disutility from pollution, where $e_{t}$ denotes the stock of pollution in period $t$. Without loss of generality, we simplify the notations below by normalizing the number of individuals in each generation to one. The instantaneous utility function faced by a young and old individual, respectively, of generation $t$ is given by

$$
\begin{gathered}
u_{t}^{y}=u^{y}\left(c_{t}, z_{t}, e_{t}-\alpha e_{t-1}\right)=c_{t}+h\left(z_{t}\right)+\psi\left(e_{t}-\alpha e_{t-1}\right), \\
u_{t+1}^{o}=u^{o}\left(x_{t+1}, e_{t+1}-\alpha e_{t}\right)=q\left(x_{t+1}\right)+\psi\left(e_{t+1}-\alpha e_{t}\right),
\end{gathered}
$$

where super-scripts $y$ and $o$ refer to “young” and “old”, respectively, and sub-script $t$ to time period. In equation (1b), the dependence of utility on leisure has been suppressed, since the

\footnotetext{
${ }^{3}$ Permanent noise exposure, for instance, may lead to sensitization (see Frederick and Loewenstein 1999).
} 
individual is assumed to be retired when old. The parameter $\alpha$ indicates the degree of adaptation or degree of sensitization to the environmental damage. We can think of $e_{t}-\alpha e_{t-1}=\Delta_{t}$ and $e_{t+1}-\alpha e_{t}=\Delta_{t+1}$ as "adaptation-adjusted" measures of the environmental damage in period $t$ and $t+1$, respectively, to be further discussed below. The functions $h(\cdot)$ and $q(\cdot)$ are increasing in their respective arguments strictly concave, while $\psi(\cdot)$ is decreasing and strictly concave with $\psi(0)=0$ and $\psi_{\Delta}(0)=\partial \psi(0) / \partial \Delta=0$. The functional form assumptions in equations (1a) and (1b) are analytically convenient by allowing us to abstract from environmental feedback effects and income effects; yet, neither additive separability nor quasilinearity is essential for the qualitative insights presented below. ${ }^{4}$

We adopt Loewenstein, O’Donoghue and Rabin’s (2003) idea of internal habit formation such that last period's stock of pollution serves as a reference measure with which the current stock is compared, ${ }^{5}$ whereby we allow not only for adaptation but also for sensitization. To begin with, the degree of adaptation/sensitization is the same for everybody. We allow the parameter $\alpha$ to be in the interval $[-1,+1]: \alpha=1$ means full adaptation (or habituation) and $\alpha=-1$ means full sensitization, although most discussion below is based on the assumption that people adapt (such that $\alpha \in(0,1])$ rather than become more sensitive to environmental damage. Of course, adaptation abilities may be quite different among people but we postpone the discussion about heterogeneity among individuals in terms of adaptation/sensitization to Section 4. Here, we stick to the simplified case of uniform adaptation behavior for the sake of the argument. Based on equations (1a) and (1b), the life-time utility function faced by an individual of generation $t$ can then be written as

$$
U_{t}=u_{t}^{y}+u_{t+1}^{o} \Theta
$$

in which $\Theta$ indicates the utility discount factor, i.e., $\Theta=1 /(1+\theta)$ where $\theta$ denotes the utility discount rate. The life-time budget constraint becomes

$$
w_{t} l_{t}+b_{t}-s_{t}=c_{t}
$$

\footnotetext{
${ }^{4}$ We abstract from adaptation in consumption and leisure. The qualitative effects of adaptation to environmental damage (the main concern here) do not depend on whether or not consumers also adapt in other dimensions.

${ }^{5}$ See also Becker and Murphy (1988).
} 


$$
s_{t}\left(1+r_{t+1}\right)=x_{t+1} \text {, }
$$

where $l$ denotes the hours of work, defined by a time endowment (normalized to one) less the time spent on leisure, i.e., $l=1-z$, while $w$ denotes the before-tax wage rate, $s$ savings and $r$ the interest rate. The variable $b$ is a lump-sum transfer paid to each young consumer, which equals the tax revenue raised through environmental taxation (see below). ${ }^{6}$

An individual of generation $t$ chooses $l_{t}$ and $s_{t}$ to maximize the life-time utility given by equation (2) subject to the life-time budget constraint presented in equations (3). Also, each individual is assumed to behave as an atomistic agent, treating factor prices, the lump-sum transfer and the stock of pollution as exogenous. The first order conditions for work hours and saving then become

$$
\begin{gathered}
u_{t, c}^{y} w_{t}-u_{t, z}^{y}=0, \\
-u_{t, c}^{y}+u_{t+1, x}^{o} \Theta\left[1+r_{t+1}\right]=0,
\end{gathered}
$$

in which the second sub-script denotes partial derivative, i.e., $u_{t, c}^{y}=\partial u_{t}^{y} / \partial c_{t}, u_{t, \mathrm{z}}^{y}=\partial u_{t}^{y} / \partial z_{t}$ and $u_{t+1, \mathrm{x}}^{o}=\partial u_{t+1}^{o} / \partial x_{t+1}$.

The homogenous consumption good is produced by identical and competitive firms under constant returns to scale, and the number of such firms is normalized to one for notational convenience. The objective function of the representative firm in period $t$ is written as

$$
F\left(l_{t}, k_{t}\right)\left(1-\tau_{t}\right)-w_{t} l_{t}-r_{t} k_{t}
$$

where $F(\cdot)$ denotes the production function, $k$ the capital stock, and $\tau_{t}$ an output tax levied on the firm in period $t$. The firm then obeys the first order conditions

$$
F_{t, l}\left(1-\tau_{t}\right)=w_{t} \text { and } F_{t, k}\left(1-\tau_{t}\right)=r_{t},
$$

where $F_{t, l}=\partial F\left(l_{t}, k_{t}\right) / \partial l_{t}$ and $F_{t, k}=\partial F\left(l_{t}, k_{t}\right) / \partial k_{t}$.

\section{Accumulation of pollution}

We assume that pollution is a state variable, which accumulates as follows:

\footnotetext{
${ }^{6}$ Since we are solely concerned with efficiency aspects of environmental policy, it is not important for the results whether the tax revenue is returned to the young or old age-group; the same tax policy implications of adaptation as those presented below would follow if the tax revenue is used as a lump-sum payment to the old.
} 


$$
e_{t}=\rho_{t} F\left(l_{t}, k_{t}\right)+(1-\delta) e_{t-1} .
$$

The parameter $\delta$ represents physical depreciation of the stock of pollution, which in the case of greenhouse gases may be close to zero. As indicated above, the additions to the stock of pollution are assumed to be proportional to output, where the factor of proportionality $\rho_{t}$ is fixed within each period although it may vary over time. Such a setting encompasses special cases of switches from dirty ( $\rho>0)$ to clean $(\rho=0)$ technologies as time passes.

\section{The government}

The government attempts to correct for the environmental damage in a way that maximizes a utilitarian social welfare function, which is given by the discounted sum of adjusted life-time utilities over generations

$$
W=\sum_{t} U_{t} \Theta^{t}
$$

By assuming that the capital stock in period $t$ equals the savings in period $t-1$, and then using equations (3) and (5a) together with the condition for government budget balance, i.e., $b_{t}=\tau_{t} F\left(l_{t}, k_{t}\right)$, the resource constraint for the economy as a whole is given as follows:

$$
F\left(l_{t}, k_{t}\right)=c_{t}+x_{t}+k_{t+1}-k_{t} \text { for all } t \text {, }
$$

meaning that output in any period is used for private consumption and net investment.

The resource allocation preferred by the government can be derived by choosing $c_{t}, l_{t}$, $x_{t}, k_{t}$ and $e_{t}$ for all $t$ to maximize the social welfare function given in equation (7) subject to the resource constraint and accumulation equation for the stock of pollution given by equation (8) and (6), respectively. The Lagrangean can then be written as

$$
L=W+\sum_{t} \gamma_{t}\left[F\left(l_{t}, k_{t}\right)+k_{t}-c_{t}-x_{t}-k_{t+1}\right]+\sum_{t} \mu_{t}\left[e_{t}-\rho_{t} F\left(l_{t}, k_{t}\right)-(1-\delta) e_{t-1}\right] .
$$

The Lagrange multipliers, $\gamma$ and $\mu$, are interpretable as present value shadow prices of physical capital and environmental quality (the negative of pollution), respectively. This will be discussed more thoroughly below. The allocation for generation $t$ preferred by the government, represented by the first order conditions for $c_{t}, l_{t}, x_{t+1}, k_{t+1}$ and $e_{t}$, are given as 


$$
\begin{gathered}
u_{t, c}^{y} \Theta^{t}-\gamma_{t}=0, \\
-u_{t, \mathrm{z}}^{y} \Theta^{t}+\gamma_{t} F_{t, l}-\mu_{t} \rho_{t} F_{t, l}=0, \\
u_{t+1, x}^{o} \Theta^{t+1}-\gamma_{t+1}=0, \\
-\gamma_{t}+\gamma_{t+1}\left(1+F_{t+1, k}\right)-\mu_{t+1} \rho_{t+1} F_{t+1, k}=0, \\
{\left[u_{t, \Delta_{t}}^{y}+u_{t, \Delta_{t}}^{o}\right] \Theta^{t}-\alpha\left[u_{t+1, \Delta_{t+1}}^{y}+u_{t+1, \Delta_{t+1}}^{o}\right] \Theta^{t+1}+\mu_{t}-\mu_{t+1}(1-\delta)=0,}
\end{gathered}
$$

where we have used the short notation $\Delta_{t}=e_{t}-\alpha e_{t-1}$ as defined above to denote the adaptationadjusted environmental damage, i.e., the measure of environmental pollution affecting individuals in period $t$. We start by deriving the policy rules for optimal output taxation in terms of the shadow price of pollution and then continue by analyzing this shadow price in more detail.

\section{Optimal tax policy}

We analyze the optimal environmental tax policy for any generation $t$. A marginal environmental tax on output can be derived by combining the first order conditions for the firm with the social first order condition for consumption and work hours attached to the young of generation $t$ given in equations (10a) and (10b). We have derived the following result, which serves as a starting point for the analysis of corrective taxation.

Lemma 1. The optimal marginal output tax can be characterized as follows:

$$
\tau_{t}=\frac{\mu_{t}}{\gamma_{t}} \rho_{t}=\frac{\mu_{t}}{\Theta^{t}} \rho_{t}=\mu_{t}(1+\theta)^{t} \rho_{t} \text { for all } t
$$

Proof: see the Appendix.

The intuition behind Lemma 1 is straightforward. The variable $\mu_{t}(1+\theta)^{t}$ represents the current value shadow price in period $t$ of a small reduction of the $e_{t}$, which is equal to the sum of marginal willingness to pay over all future generations for this small reduction of $e_{t}$ measured in private consumption (having $u_{t, c}^{y}=1$ ). The value of the marginal externality generated through production in period $t$ is equal to $\mu_{t}(1+\theta)^{t}$ times the marginal effect of period $t$ output 
on emission, $\rho_{t}$. Equation (13) thus represents a first-best Pigouvian tax on the intertemporal externality. ${ }^{7}$

Let us start by analyzing the standard case where there is no adaptation or sensitization to environmental damage. This might be thought of as a reference case in the analysis to follow. By solving the difference equation (10e) under the assumption that $\alpha=0$, and then using Lemma 1, we obtain the following result:

\section{Observation 1 (green benchmark policy). Without any adaptation or sensitization}

to the environmental damage, i.e., if $\alpha=0$, we have

$$
\begin{aligned}
\mu_{t} & =-\sum_{s=0}^{\infty}\left[u_{t+s, \Delta_{t+s}}^{y}+u_{t+s, \Delta_{t+s}}^{o}\right] \Theta^{t+s}(1-\delta)^{s} \\
& =-2 \sum_{s=0}^{\infty} \psi_{e}\left(e_{t+s}\right) \Theta^{t+s}(1-\delta)^{s}>0
\end{aligned}
$$

such that $\rho_{t}>0$ implies $\tau_{t}>0$ for all $t$.

Observation 1 means that without any adaptation or sensitization, the shadow price $\mu_{t}$ becomes equal to the negative of the standard discounted sum of marginal utilities of pollution measured over all future generations, times the remaining part of this marginal unit of pollution $(1-\delta)$ in the periods following period $t$.

With adaptation or sensitization such that $\alpha \neq 0$, Observation 1 is no longer valid in general. The shadow price of environmental quality is then given by

$$
\begin{aligned}
\mu_{t} & =-\sum_{s=0}^{\infty}\left[\left\{u_{t+s, \Delta_{t+s}}^{y}+u_{t+s, \Delta_{t+s}}^{o}\right\}-\alpha\left\{u_{t+s+1, \Delta_{t+s+1}}^{y}+u_{t+s+1, \Delta_{t+s+1}}^{o}\right\} \Theta\right] \Theta^{t+s}(1-\delta)^{s} \\
& =-2 \sum_{s=0}^{\infty}\left[\psi_{\Delta}\left(e_{t+s}-\alpha e_{t+s-1}\right)-\alpha \psi_{\Delta}\left(e_{t+s+1}-\alpha e_{t+s}\right) \Theta\right] \Theta^{t+s}(1-\delta)^{s}
\end{aligned}
$$

In equation (15), $u_{t, \Delta_{t}}^{y}=u_{t, \Delta_{t}}^{o}=\psi_{\Delta}\left(e_{t}-\alpha e_{t-1}\right)$ denotes the marginal utility of pollution faced by any (young or old) individual living in period $t$, which depends on the adaptation-adjusted measure of pollution, $e_{t}-\alpha e_{t-1}$. Since we assume a quasi-linear utility function, we can

\footnotetext{
${ }^{7}$ Since the production sector is characterized by constant returns to scale, an alternative way of implementing the first best optimum (as perceived by the utilitarian government described above) would be to use income taxation, where marginal labor income taxes and marginal capital income taxes are implemented in order to decrease the hours of work and savings, respectively, with the same implication as the output tax described here.
} 
interpret $-\psi_{\Delta}\left(e_{t}-\alpha e_{t-1}\right) \Theta^{-t}$ as the marginal willingness to pay by any such consumer to avoid pollution in period $t$, ceteris paribus.

The second component in the square bracket on the right hand side of equation (15), i.e., the expression proportional to $\alpha$, is due to the fact that increased pollution today affects the marginal utility of pollution in the future. With adaptation, i.e., $\alpha \in(0,1]$, this component works to reduce the shadow price of pollution and, therefore, most likely the optimal level of the corrective policy measure, whereas sensitization such that $\alpha \in[-1,0)$ works the other way around. To see this more clearly, let us differentiate equation (15) with respect to $\alpha$ and evaluate the resulting derivative at $\alpha=0$. As such, we are measuring how the shadow price of environmental quality reacts to a small increase in the degree of adaptation (or sensitization if we take the negative of this derivative) compared to the green benchmark case without any adaptation or sensitization.

Lemma 2. $\left.\frac{\partial \mu_{t}}{\partial \alpha}\right|_{\alpha=0}<0$ for all $t$ if $\frac{\partial e_{t}}{\partial \alpha} \leq 1$ for all $t$.

Proof: see the Appendix.

We can then use Lemmas 1 and 2 to derive the following result:

Proposition 1. Under the conditions of Lemma 2, $\left.\frac{\partial \tau_{t}}{\partial \alpha}\right|_{\alpha=0}<0$ if $\rho_{t}>0$.

Proposition 1 means that a small increase in the degree of adaptation (an increase in $\alpha$ ) leads to lower marginal taxation of output in period $t$, and, conversely, that a small increase in the degree of sensitization (a decrease in $\alpha$ ) leads to higher marginal taxation of output in period $t$, compared to the benchmark case without any adaptation or sensitization. Note also that Lemma 2 gives a sufficient (not necessary) condition for a negative relationship between the shadow price of environmental quality and the degree of adaptation, since the derivative of $\mu_{t}$ with respect to $\alpha$ (evaluated at the point where $\alpha=0$ ) can clearly be negative even if $\partial e_{t} / \partial \alpha>1$ for all $t$. The requirement $\partial e_{t} / \partial \alpha \leq 1$ ensures that the direct negative effect of $\alpha$ on the marginal willingness to pay for environmental quality is not fully offset by a corresponding indirect effect through increased pollution. 
Notice that if the stock of pollution is constant over time at the level $\bar{e}$, equation (15) changes to read

$$
\mu_{t}=-2 \psi_{\Delta}(\bar{e}-\alpha \bar{e}) \frac{1-\alpha+\theta}{1+\theta} \sum_{s=0}^{\infty} \Theta^{t+s}(1-\delta)^{s} .
$$

The multiplier $(1-\alpha+\theta) /(1+\theta)$ is interpretable as a weight that adaptation/sensitization gives to the marginal utility of pollution in the shadow price formula. Without any adaptation/sensitization (i.e., $\alpha=0$ ), this weight is equal to one. Therefore, adaptation decreases the weight given to the marginal utility of pollution below unity, whereas sensitization increases the weight above unity. Equation (16) is particularly useful in order to characterize the implications of full adaptation, in which case $\alpha=1$.

Proposition 2. Suppose that the stock of pollution is constant over time. With full adaptation such that $\alpha=1$, then $\tau_{t}=0$ for all $t$.

Proposition 2 is a remarkable result. One interpretation is that the economy has reached a stationary equilibrium (steady state). If $\rho$ is time-invariant (i.e., $\rho_{t}=\rho>0$ for all $t$ ) and if the economy has reached a steady state where production is constant over time, then the stock of pollution is also constant. Full adaptation then means that a conventional welfarist government refrains from taxing pollution since full adaptation implies that the marginal disutility of pollution approaches zero. As such, pollution taxes or subsidies are only used along the transitional path. For instance, if the stock of pollution increases at a decreasing rate such that $e_{t}-e_{t-1}>e_{t+1}-e_{t}>0$ for all $t$ along the transitional path, the marginal pollution tax is positive (yet decreasing) along this path, while it becomes equal to zero once the steady state is reached.

Another interpretation is based on a case where both the contributions to the stock of pollution and the natural depreciation of pollution are very small, although the economy has not reached a stationary equilibrium; a possible future scenario for carbon dioxide pollution, if production technologies become cleaner. Also in that case, the stock of pollution would be roughly constant. As above, therefore, full adaptation means that a welfarist government has no incentive to use corrective measures to combat the release of emissions.

The case where the production technology becomes cleaner over time is also interesting for another reason. To see this, suppose that $\rho_{0}>0, \rho_{t}=0$ for $t>0$ and $\delta=0$. Note also that 
this case implies $\tau_{0}>0$, and $\tau_{t}=0$ for $t>0$, irrespective of whether people adapt to the environmental damage. Yet, the shadow price on which the first period marginal tax rate is based takes a much simpler form under full adaptation

$$
\begin{aligned}
\mu_{0} & =-[u_{0, \Delta_{0}}^{y}+u_{0, \Delta_{0}}^{0}-\underbrace{\left\{u_{1, \Delta_{1}}^{y}+u_{1, \Delta_{1}}^{o}\right\}}_{=0} \Theta] \\
& -\underbrace{\sum_{s=1}^{\infty}\left[\left\{u_{s, \Delta_{s}}^{y}+u_{s, \Delta_{s}}^{o}\right\}-\left\{u_{s+1, \Delta_{s+1}}^{y}+u_{s+1, \Delta_{s+1}}^{o}\right\} \Theta \Theta^{s}\right.}_{=0} \\
& =-2 \psi_{\Delta}\left(e_{0}-\bar{e}_{0-1}\right)
\end{aligned}
$$

where $\bar{e}_{0-1}$ is a fixed (and predetermined) stock of pollution at the beginning of period 0 , and $\Delta_{0}=\bar{e}_{0}-\bar{e}_{0-1}$. Notice that the shadow price is only based on the marginal utility of pollution among those alive in period 0 , since the marginal utility of pollution is zero for all future generations, which do not suffer from the remaining stock of pollution under full adaptation.

\section{Heterogeneity in the ability to adapt}

So far we have focused on the case where all individuals have the same ability to adapt, i.e., $\alpha$ is the same for all individuals in each generation. Psychological research suggests that variables such as personality traits that predispose individuals to experience-specific life events explain heterogeneity in the ability to adapt (for further references, see Luhmann et al. 2012). The

results by Albouy et al. (2013), who analyze U.S. households' preferences over local climates, show that preferences vary by location due to sorting or adaptation indicating the potential importance of heterogeneity in adaptation with respect to future climate change. We analyze this case by assuming that only a share of the population $0 \leq \beta \leq 1$ is able to adapt, i.e., $\alpha \neq 0$, while the share $1-\beta$ is not able to adapt, i.e., $\alpha=0$.

If people face the same preferences but only differ in the degree of adaptation, the welfarist model with a utilitarian government will lead to a modified cost-benefit analysis compared to above.

The social welfare function can then be written as 


$$
W=\beta \sum_{t} U_{t}^{a} \Theta^{t}+(1-\beta) \sum_{t} U_{t}^{n} \Theta^{t}
$$

where super-script $a$ refers to adapters and $n$ to non-adapters. Also, to focus on heterogeneity with respect to adaptation, we assume that the individuals are identical in all other respects. The resource constraint and accumulation equation for environmental damage take the same form as above. Since we assume that individuals have the same preferences, and that the utility function is separable in the environmental damage, the social first order conditions for consumption and work hours do not differ between adapters and non-adapters. Therefore, the social first order conditions for $c_{t}, l_{t}, x_{t+1}$ and $k_{t+1}$ will remain as in equations (10a)-(10d), whereas the social first order condition for $e_{t}$ changes to read

$$
\begin{gathered}
\beta\left[\left\{u_{t, \Delta_{t}}^{y, a}+u_{t, \Delta_{t}}^{o, a}\right\} \Theta^{t}-\alpha\left\{u_{t+1, \Delta_{t+1}}^{y, a}+u_{t+1, \Delta_{t+1}}^{o, a}\right\} \Theta^{t+1}\right]+(1-\beta)\left[u_{t, \Delta_{t}}^{y, n}+u_{t, \Delta_{t}}^{o, n}\right] \Theta^{t} \\
+\mu_{t}-\mu_{t+1}(1-\delta)=0
\end{gathered}
$$

With equation (19) at our disposal, the following result immediately follows from Lemma 1:

Proposition 3. If only a fraction $\beta$ of the population adapts to the pollution, $a$ welfarist government implements the first best through the following tax policy

$$
\begin{aligned}
\tau_{t}= & \frac{\mu_{t}}{\Theta^{t}} \rho_{t}=-\rho_{t} \beta \sum_{s=0}^{\infty}\left[\left\{u_{t+s, \Delta_{t+s}}^{y, a}+u_{t+s, \Delta_{t+s}}^{o, a}\right\}-\alpha\left\{u_{t+s+1, \Delta_{t+s+1}}^{y, a}+u_{t+s+1, \Delta_{t+s+1}}^{o, a}\right\} \Theta\right] \Theta^{s}(1-\delta)^{s} \\
& -\rho_{t}(1-\beta) \sum_{s=0}^{\infty}\left[u_{t+s, \Delta_{t+s}}^{y, n}+u_{t+s, \Delta_{t+s}}^{o, n}\right] \Theta^{s}(1-\delta)^{s} \\
= & -2 \rho_{t} \sum_{s=0}^{\infty} \Theta^{s}(1-\delta)^{s}\left[\beta\left\{\psi_{\Delta}\left(e_{t+s}-\alpha e_{t+s-1}\right)-\alpha \psi_{\Delta}\left(e_{t+s+1}-\alpha e_{t+s}\right) \Theta\right\}+(1-\beta) \psi_{\Delta}\left(e_{t+s}\right)\right]
\end{aligned}
$$

Proof: see the Appendix.

Proposition 3 implies that the formula for the externality correcting pollution tax becomes a linear combination of the formulas for adapters and non-adapters. For any given resource allocation (which means a given path for the stock of pollution), a higher share of adapters implies a lower optimal pollution tax for a utilitarian government that recognizes the assumed tendency to adapt among consumers. Lowering the pollution tax in response to adaptation 
makes the non-adapters worse off. ${ }^{8}$ As long as at least some people adapt to the environmental damage, therefore, the application of the conventional tax formula in Observation 1 (which assumes away adaptation completely) typically leads to excessive taxation. Again, the interpretation in terms of sensitization is analogous: the standard tax formula in Observation 1 would in that case imply a too low tax.

Heterogeneity in the ability to psychologically adapt may also have severe implications for intergenerational redistribution, an issue thoroughly discussed by Stern (2007) in the context of technological adaptation. Early in the debate about climate change, Thomas Schelling (1992) suggested that highly developed, richer societies are less vulnerable to climate change as they have the financial and human capital, the knowledge and the appropriate technologies for an optimal reaction to climate change while poor societies lack the capability to cope. In so far as technological adaptation is positively correlated with psychological adaptation, this so-called "Schelling-conjecture” (Anthoff and Tol 2012) carries over to the case of psychological adaptation. Indeed, Proposition 3 implies that taking psychological adaptation into account may worsen the imbalance of costs borne by future poor and rich societies. A purely efficiencyoriented policy that gives equal weight to all individuals would harm the non-adapters and thus lead to an intertemporal redistribution of welfare from future non-adapters to the current producing generation. When we introduce redistributive concerns in a social welfare function of the Bergson-Samuelson type, and if heterogeneity in the ability to adapt is not perfectly correlated with income, then we have a new dimension of redistribution that is not considered in standard social welfare functions. Hence, taking account of psychological adaptation and the potential heterogeneity of adaptation ability raises severe normative questions.

\section{Discussion}

Climate policy hardly anticipates psychological adaptation or sensitization processes adaquately and thus cannot claim to provide reliable cost-benefit estimates for climate change.

\footnotetext{
${ }^{8}$ Consider once again the special case with full adaptation (among the adapters), a constant $\rho$, and a constant stock of pollution, in which case equation (20) reduces to read $\tau=-2 \rho(1-\beta) \psi_{\Delta}(\bar{e}) \sum_{s=0}^{\infty} \Theta^{s}(1-\delta)^{s}$. For a given $\bar{e}$, therefore, the optimal tax is a fraction $1-\beta$ of the standard Pigouvian tax.
} 
Information about these processes are needed in order to improve intertemporal efforts to minimize the social cost of global warming. Here, further research on psychological adaptation promises high returns. ${ }^{9}$

Of course, the psychological perspective on adaptation as quoted in the introduction includes many of the aspects the IPCC has in mind with its definition of techological adaptation, but goes far beyond these as it encompasses adaptation processes triggered by both affective and cognitive reactions. Both forms of adaptation may interact and reinforce each other. Climate-induced reorganization of farming may change eating habits. While the standard theory measures the loss in utility due to the induced substitution processes, a model that takes psychological adaptation into account may consider this utility loss to be transitional only and thus would predict a lower total cost of changing farming decisions in the cause of climate change. The expected rise of the sea level may result in as many as 200 million environmental refugees by the middle of the century (Myers 2002). Forced resettlements can involve high psychological cost caused by disruptions of geographic and social connections (Doherty and Clayton 2011, p. 271) as well as social and economic problems such as poverty, unemployment, and social marginalization (Barnett and O’Neill 2012, p. 9). These consequences can be alleviated by long-run adaptation policies that set incentives for people to migrate voluntarily. This may both reduce the social and economic problems and increase the individuals' ability of psychological adaptation (Barnett and O’Neill 2012). If people (and in particular the future generation) adapt to the new living conditions, this psychological adaptation, in addition to the technological adaption, can be expected to substantially reduce the ultimate cost of climate change.

Beyond its implication on intertemporal cost-benefit assessments of climate change, our analysis also has important and far-reaching normative implications. In standard welfare analysis, adaptation provides no justification for governments to intervene when individuals

\footnotetext{
9 Additionally, future environmental problems may also affect today's well-being via these psychological processes so that "climate change adaptation and mitigation are closely interlinked, in that it is one's psychological response to the climate change threat and one's changed thinking, feelings, motivations, and concerns that powerfully mediate the extent to which one engages in environmentally significant behavior" (Reser and Slim 2011, 285f).
} 
have rational expectations about their adaptation abilities (e.g., Aronsson and Schöb 2012). Furthermore, many economists discredit the idea of government intervention to correct for anticipation biases as paternalistic (Saint-Paul 2011). Yet, we have shown that in the presence of intertemporal externalities, psychological adaptation to environmental damage should play a crucial role in the design of an optimal policy. In the government's intertemporal decision problem, today's decision must be based on the best available information about both today's cost of mitigation and tomorrow's cost of coping with the consequences of today's decisions. And these future consequences crucially depend on the future generations' ability to adapt, both technologically and psychologically. Psychological adaptation (as well as sensitization) must, therefore, be considered in a comprehensive cost-benefit analysis of a welfare-maximizing government. Thus, it is the denial of the importance of psychological adaptation processes that would make today's government paternalistic - by putting the future generation ahead of the current generation.

\section{Appendix}

Proof of Lemma 1: Combining equations (10a) and (10b) gives

$$
\gamma_{t}\left[F_{t, l}-\frac{u_{t, z}^{y}}{u_{t, c}^{1}}\right]=\mu_{t} \rho_{t} F_{t, l}
$$

Use the individual first order condition for work hours, $w_{t}-u_{t, z}^{y} / u_{t, c}^{1}=0$, and the firm's first order condition for labor input, $\left(1-\tau_{t}\right) F_{t, l}=w_{t}$, to derive $F_{t, l}-u_{t, z}^{y} / u_{t, c}^{1}=\tau_{t} F_{t, l}$. Substituting into equation (A1) gives equation (13).

Proof of Lemma 2: Differentiating equation (15) with respect to $\alpha$ and evaluating the resulting derivative at the point where $\alpha=0$ implies

$$
\left.\frac{\partial \mu_{t}}{\partial \alpha}\right|_{\alpha=0}=-2 \sum_{s}\left[-\psi_{\Delta \Delta}\left(e_{t+s}\right)\left(1-\frac{\partial e_{t+s}}{\partial \alpha}\right)-\psi_{\Delta}\left(e_{t+s+1}\right)\right]
$$

where $\psi_{\Delta}\left(e_{t+s}\right)<0$ and $\psi_{\Delta \Delta}\left(e_{t+s}\right)<0$ for all s. A sufficient condition for the right hand side of equation (A2) to be negative is $\partial e_{t+s} / \partial \alpha \leq 1$ for all $s$. 
Proof of Proposition 3: Solve equation (19) forwards to derive

$$
\begin{aligned}
\mu_{t} & =-\sum_{s=0}^{\infty} \beta\left[\left\{u_{t+s, \Delta_{t+s}}^{y, a}+u_{t+s, \Delta_{t+s}}^{o, a}\right\}-\alpha\left\{u_{t+s+1, \Delta_{t+s+1}}^{y, a}+u_{t+s+1, \Delta_{t+s+1}}^{o, a}\right\} \Theta \Theta^{t+s}(1-\delta)^{s}\right. \\
& -\sum_{s=0}^{\infty}(1-\beta)\left[u_{t+s, \Delta_{t+s}}^{y, a}+u_{t+s, \Delta_{t+s}}^{o, a}\right] \Theta^{t+s}(1-\delta)^{s} \\
& =-2 \sum_{s=0}^{\infty} \beta\left[\psi_{\Delta}\left(e_{t+s}-\alpha e_{t+s-1}\right)-\alpha \psi_{\Delta}\left(e_{t+s+1}-\alpha e_{t+s}\right) \Theta\right] \Theta^{t+s}(1-\delta)^{s} \\
& -2 \sum_{s=0}^{\infty}(1-\beta)\left[\psi_{\Delta}\left(e_{t+s}\right)\right] \Theta^{t+s}(1-\delta)^{s}
\end{aligned}
$$

Substituting into equation (13) gives equation (20).

\section{References}

Albouy, David, Walter F. Graf, Ryan Kellogg, and Hendrik Wolff (2013): Climate Amenities, Climate Change, and American Quality of Life, NBER Working Paper No. 18925, March.

American Psychological Association Task Force on the Interface Between Psychology and Global Climate Change (2009): Psychology and global climate change: Addressing a multi-faceted phenomenon and set of challenges. Retrieved from http://www.apa.org/science/about/publications/climate-change.aspx.

Anthoff, David, and Richard S. J. Tol (2012): "Schelling's conjecture on climate and development: a test”, in Robert William Hahn and Alastair Ulph (eds.): Climate Change and Common Sense: Essays in Honour of Tom Schelling, Oxford University Press: Oxford, 260-273.

Aronsson, Thomas, and Ronnie Schöb (2012): Adaptation, Anticipation-Bias and Optimal Income Taxation, CESifo Working Paper No. 3840, June.

Barnett, Jon, and Saffron J. O’Neill (2012): “Islands, resettlement and adaptation”, Nature Climate Change 2, 8-10.

Becker, G. and Murphy, K. (1988): “A Theory of Rational Addiction”, Journal of Political Economy 96, 675-700.

Diener, Ed, Richard E. Lucas, and Christie N. Scollon (2006): "Beyond the hedonic treadmill Revising the adaptation theory of well-being”, American Psychologist 61(5), 305-314.

Doherty, Thomas J. and Susan Clayton (2011): "The Psychological Impacts of Global Climate Change”, American Psychologist 66(4), 265-276.

Frederick, Shane, and George Loewenstein (1999): “Hedonic adaptation”, in Daniel Kahneman, Ed Diener, and Norbert Schwarz (eds.): Well-being: The foundations of hedonic psychology, New York: Russell Sage, 302-329.

Gore, Al (1992): Earth in the Balance, Earthscan.

IPCC (2007): Climate Change 2007 - Impacts, Adaptation and Vulnerability, Contribution of Working Group II to the Fourth Assessment Report of the Intergovernmental Panel on Climate Change, Cambridge University Press: Cambridge and New York.

IIPC (2014): Climate Change 2014: Impacts, Adaptation, and Vulnerability, Summary for Policymakers of Working Group II, Fifth Assessment Report of the Intergovernmental Panel on Climate Change (IPCC), Approved SPM 31 March 2014.

Kahneman, Daniel, and Richard H. Thaler (2006): “Anomalies: Utility maximization and experienced utility”, Journal of Economic Perspectives 20, 221-234. 
Konrad, Kai A., and Marcel Thum (2014): “The Role of Economic Policy in Climate Change Adaptation”, CESifo Economic Studies 60, 32-61.

Loewenstein, George, Ted O’Donoghue, and Matthew Rabin (2003): “Projection bias in predicting future utility”, Quarterly Journal of Economics 118, 1209-1248.

Lucas, Richard E. (2007): “Adaptation and the set-point model of subjective well-being - Does happiness change after major life events?”, Current Directions in Psychological Science 16(2), 75-79.

Luhmann, Maike, Wilhelm Hofmann, Michael Eid and Richard E. Lucas (2012): "Subjective well-being and adaptation to life events: A meta-analysis”, Journal of Personality and Social Psychology 102, 592-615.

Lyubormirsky, Sonja (2011): "Hedonic adaptation to positive and negative experiences”, in Susan Folkman (ed.): Oxford Handbook of Stress, Health, and Coping, Oxford University Press: Oxford, 200-224.

Myers, Norman (2002): "Environmental refugees: a growing phenomenon of the $21^{\text {st }}$ century", Philosophical Transactions of the Royal Society B 357, 609-613.

OECD (2008): Economic Aspects of Adaptation to Climate Change, Costs, Benefits and Policy Instruments, OECD Publishing: Paris.

OECD (2012): Environmental Outlook to 2050, OECD Publishing: Paris.

Pielke, Roger Jr., Gwyn Prins, Steve Rayner and Daniel Sarewitz (2007): "Lifting the taboo on adaptation”, Nature 445, 597-598.

Perez-Truglia, Ricardo (2012): “On the causes and consequences of hedonic adaptation”, Journal of Economic Psychology 33(6), 1182-1192.

Rayo, Luis, and Gary Becker (2007): "Evolutionary Efficiency and Happiness,” Journal of Political Economy 115(2), 302-337.

Reser, Joseph P., and Janet K. Slim (2011): “Adapting to and coping with the threat and impacts of climate change”, American Psychologist 66, 277-289.

Riis, Jason, et al. (2005): "Ignorance of Hedonic Adaptation to Hemodialysis: A Study Using Ecological Momentary Assessment”, Journal of Experimental Psychology: General, 134(1), 3-9.

Robson, Arthur (2002): “Evolution and human nature”, Journal of Economic Literature 16(2), 89-102.

Sackett, David L., and George W. Torrance (1978): "Utility of Different Health States as Perceived by General Public”, Journal of Chronic Diseases 31, 697-704.

Saint-Paul, Gilles (2011): The Tyranny of Utility, Princeton University Press: Princeton Mass.

Schelling, Thomas C. (1992): “Some economics of global warming”, American Economic Review 82(1), 1-14.

Schkade, David A., and Daniel Kahneman (1998): "Does living in California make people happy? A focusing illusion in judgments of life satisfaction”, Psychological Science 9, 340-346.

Stern, Nicholas (2007): The Economics of Climate Change: The Stern Review, Cambridge University Press: Cambridge.

Wilson, Timothy D., and Daniel T. Gilbert (2003): “Affective forecasting”, Advances in Experimental Social Psychology 35, 345-411.

Wilson, Timothy D., and Daniel T. Gilbert (2008): "Explaining Away: A Model of Affective Adaptation”, Perspectives on Psychological Science 3, 370-386. 